\title{
Health outcomes during the 2008 financial crisis in Europe: systematic literature review
}

\author{
Divya Parmar, ${ }^{1}$ Charitini Stavropoulou, ${ }^{1}$ John P A Ioannidis ${ }^{2}$
}

'School of Health Sciences, City University London, London

EC1V OHB, UK

2School of Medicine, Stanford University, Stanford, CA, USA

Correspondence to:

CStavropoulou

C.Stavropoulou@city.ac.uk

Additional material is published online only. To view please visit

the journal online.

Cite this as: $B M J$ 2016;354:i4588

http://dx.doi.org/10.1136/bmj.

i4588

Accepted: 20 July 2016

\section{ABSTRACT}

OBJECTIVE

To systematically identify, critically appraise, and synthesise empirical studies about the impact of the 2008 financial crisis in Europe on health outcomes.

DESIGN

Systematic literature review.

\section{DATA SOURCES}

Structural searches of key databases, healthcare journals, and organisation based websites.

\section{REVIEW METHODS}

Empirical studies reporting on the impact of the financial crisis on health outcomes in Europe, published from January 2008 to December 2015, were included. All selected studies were assessed for risk of bias. Owing to the heterogeneity of studies in terms of study design and analysis and the use of overlapping datasets across studies, studies were analysed thematically per outcome, and the evidence was synthesised on different health outcomes without formal meta-analysis. RESULTS

41 studies met the inclusion criteria, and focused on suicide, mental health, self rated health, mortality, and other health outcomes. Of those studies, 30 (73\%) were deemed to be at high risk of bias, nine $(22 \%)$ at moderate risk of bias, and only two (5\%) at low risk of bias, limiting the conclusions that can be drawn. Although there were differences across countries and groups, there was some indication that suicides increased and mental health deteriorated during the crisis. The crisis did not seem to reverse the trend of decreasing overall mortality. Evidence on self rated health and other indicators was mixed.

CONCLUSIONS

Most published studies on the impact of financial crisis on health in Europe had a substantial risk of

\section{WHAT IS ALREADY KNOWN ON THIS TOPIC}

As a result of the financial crisis in Europe that intensified in 2008, several European Union countries reduced their health budget and introduced structural changes and austerity measures

At the same time individual households experienced financial insecurity created by job loss and reduced salaries

Despite immense interest in the impact of the financial crisis in Europe, evidence on its impact on health outcomes is still unclear and fragmented

\section{WHAT THIS STUDY ADDS}

Our systematic review shows that the financial crisis in Europe seems to have had heterogeneous effects on health outcomes, with the evidence being most consistent for suicides and mental health that show deterioration

Evidence also suggests that most of the studies reviewed had a substantial risk of bias; therefore, results need to be cautiously interpreted bias; therefore, results need to be cautiously interpreted. Overall, the financial crisis in Europe seemed to have had heterogeneous effects on health outcomes, with the evidence being most consistent for suicides and mental health. There is a need for better empirical studies, especially those focused on identifying mechanisms that can mitigate the adverse effects of the crisis.

\section{Introduction}

In 2008, Europe entered a period of unprecedented financial crisis following a global economic downturn. Several countries in the European Union faced declining gross domestic product (GDP), increasing public debt, and rising borrowing costs, while individual households experienced financial insecurity created by job loss, reduced salaries, and plummeting house prices. ${ }^{1}$ The situation worsened by early 2010, and Greece became the first EU country to receive a bailout package jointly from the International Monetary Fund, the EU, and the European Central Bank. Ireland, Portugal, and Cyprus followed a few months later.

The effect of the financial crisis on European health systems was inevitable. Different countries responded with different policies. Many countries reduced their health budgets, and some had to introduce structural changes and tough austerity measures. ${ }^{2}$ Fears about the adverse impact of the financial crisis on health outcomes have been increasing, and consequently, the number of studies investigating this impact has grown in the past few years. ${ }^{34}$ It has been argued that the impact of a financial crisis is not always uniform across countries, but could depend on the duration and severity of the crisis, the type of austerity measures introduced by the government, and whether the populations are covered by social protection schemes. ${ }^{5}$

Evidence relating to previous crises is inconclusive and suggests that the impact on health outcomes can be context specific. Tapia Granados and Diez Roux ${ }^{6}$ studied the Great Depression in the USA (1929-39) and found that except for suicides, most other causes of mortality fell, but life expectancy rose during that period. By contrast, in Russia, following the breakup of the Soviet Union, life expectancy decreased by 6.6 years for men and 3.3 years for women between 1989 and 1994. ${ }^{7}$ The current financial crisis is arguably the most severe that Europe has experienced in the post-war era, threatening even the unity of the EU, with countries such as Greece facing exit in light of their debt crisis. In addition, the magnitude and geographical variation of the crisis makes it a unique context to analyse.

Yet-and despite growing interest in the impact of the financial crisis in Europe on health outcomes-the evidence so far has been fragmented. Studies focus on 
particular countries (eg, Simou and Koutsogeorgou ${ }^{8}$ on Greece), particular health outcomes (eg, van $\mathrm{Hal}^{9}$ on psychological wellbeing), or particular groups (eg, Rajmil and colleagues ${ }^{10}$ on children). The aim of this paper was to systematically identify, critically appraise, and synthesise the empirical evidence on the impact of the financial crisis in Europe on health outcomes.

\section{Methods}

Search strategy and selection process

Our steps for identifying and reviewing the evidence were based on the recommendations of the Centre for Reviews and Dissemination. ${ }^{11}$ Firstly, we conducted structured searches of online databases: PubMed, Web of Science, EBSCOhost, Scopus, and Google Scholar. Secondly, we hand searched key healthcare journals (Lancet, European Journal of Public Health, Health Policy, Social Science and Medicine, The BMJ, PLoS One, and BMJ Open). Finally, we searched the websites of relevant organisations that have published reports and data on population health and healthcare, including the World Health Organization, Organisation for Economic Co-operation and Development, European Observatory on Health Systems and Policies, and Unicef. The search terms we used included "financial crisis"; “economic crisis"; "recession”; "austerity”; in conjunction with "health"; "health outcomes"; "healthcare"; and "Europe." Supplementary table A shows the search string as applied in PubMed.

We included studies published from January 2008, when the financial crisis in Europe intensified, to December 2015. Only studies published in English were included. The search was limited to empirical, quantitative papers and excluded qualitative studies, opinion papers, commentaries, and systematic literature reviews. We excluded the following groups of studies:

- Empirical cross sectional studies with no control group - that is, a country that was not hit by the crisis

- Longitudinal studies that did not follow the same group before and after the crisis

- Studies presenting only descriptive evidence

- Studies examining the impact of the crisis on health behaviours, such as smoking, exercising, and drinking

- Studies looking at the impact of macroeconomic indicators on health outcomes in general, unless researchers specifically investigated this in the context of the current crisis-that is, by clearly defining the period of crisis

- Studies looking at the impact of the financial crisis on health systems, such as changes in health workforce.

We also excluded conference proceedings and abstracts if the full text was not available. Multicountry studies were included if their results on European countries could be identified separately.

Our research assistant searched the above websites and, along with one of the authors, initially screened titles for relevance to the topic. The research assistant and one author then screened the abstracts of the selected papers independently, and when disagreements occurred, the second author became involved.
The two authors then read and discussed the full text of the papers and excluded those that did not meet the aims of the study. In this way, we decided on the final list of papers to be included for analysis. The research assistant searched the references and citations of the selected papers. Abstracts and the full text of additional papers identified were reviewed in the same manner. This review process followed the preferred reporting items for systematic reviews and meta-analyses (PRISMA) guidelines (the PRISMA checklist is available on request). ${ }^{12}$

\section{Data extraction and analysis}

We extracted data using a standardised data extraction form. These extracted data included: country, period examined, definition of the crisis period, crisis indicator, data and population, study design and methods, main findings, and health outcome examined. Owing to the heterogeneity of the studies in terms of study design and analysis, we decided to thematically analyse them per outcome. Formal quantitative synthesis (meta-analysis) was further impeded by the fact that some studies covered overlapping questions and settings or used different analyses on overlapping datasets; whenever such an overlap existed, we pointed this out. The data extraction table is provided in the supplementary appendix (table B).

\section{Risk of bias assessment}

After considering several assessment tools for observational studies, including the Newcastle-Ottawa scale ${ }^{13}$ and the RTI item bank, ${ }^{14}$ we decided that the nature of our review and of the reviewed studies was such that none of the existing tools was suitable. For example, the Newcastle-Ottawa scale items on comparability and RTI items on performance and detection bias were not easy to operationalise for our research question. Moreover, these common scales did not include items that captured important aspects that we wanted to consider in our review. Therefore, we decided to develop our own tool. We assessed the risk of bias of the included studies over seven key domains of bias: selection bias, ecological fallacy, confounding bias, reporting bias, time bias, measurement error in exposure indicator, and measurement error in health outcome.

Three of these domains (selection bias, confounding bias, and reporting bias) are commonly captured in several scales, including the RTI item bank and Newcastle-Ottawa scale. Measurement error in health outcomes, adapted from the Newcastle-Ottawa scale, captured the heterogeneity of indicators used, which varied in terms of potential for misreporting (eg, high potential for suicides, none for all cause mortality).

The remaining three domains were included to capture important characteristics of our studies. The ecological fallacy exists when inferences are made from group averages of potential risk factors about outcomes of single individuals. The average experience might not necessarily reflect the experience at the individual level. For example, suppose that an increase in unemployment across different countries is found to be 


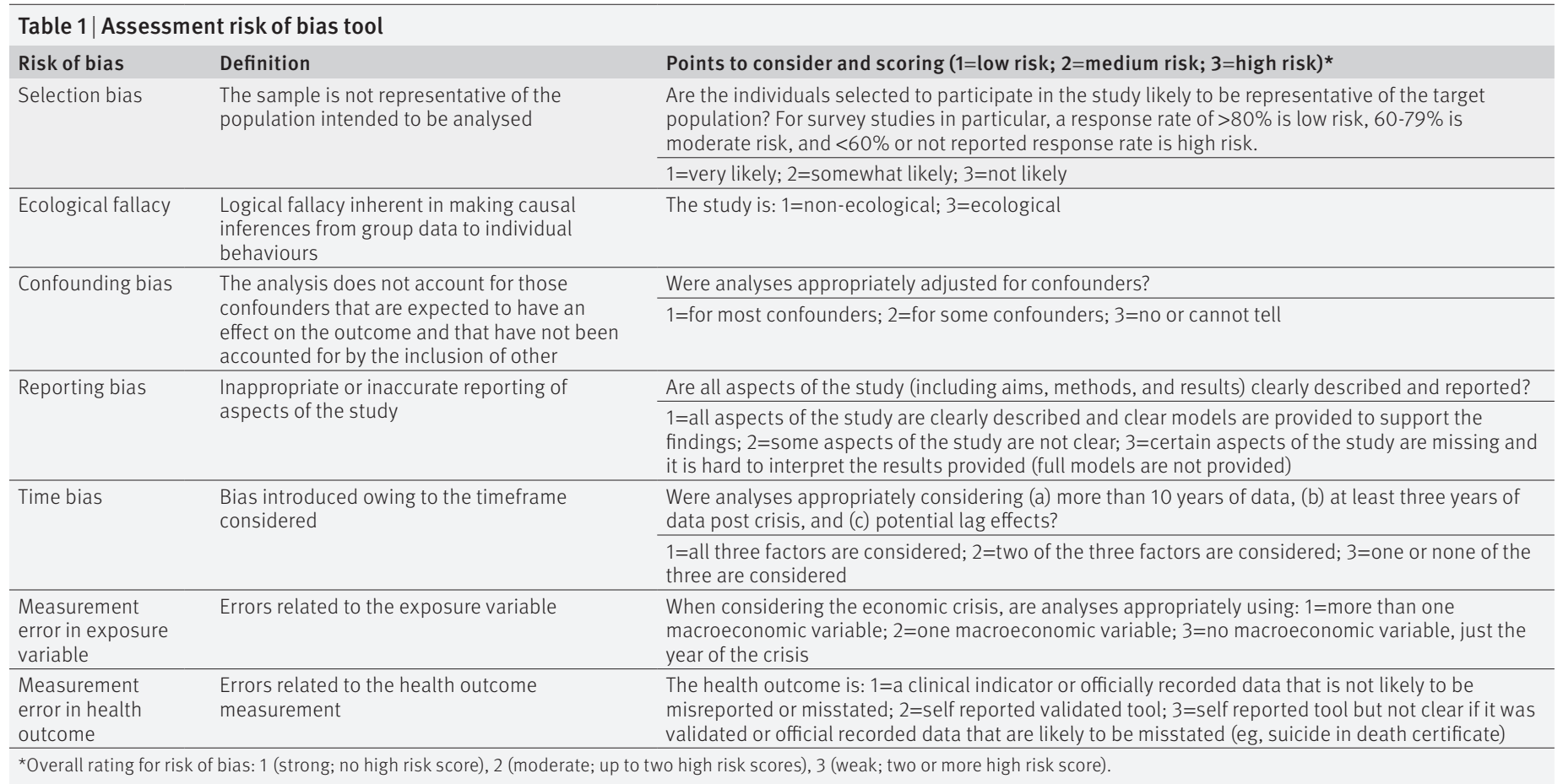

associated with increased death or suicide risk. Still, one cannot exclude the possibility that within one country, those people who committed suicide and died were actually those who were employed (but overworked and underpaid) rather than those who were unemployed. Under this scenario, if one intervened and employed the unemployed group in jobs where they are underpaid and overworked, suicides might actually increase. Time bias was considered important because previous empirical studies in the area have suggested that reliable estimates can be obtained only when long periods are considered. ${ }^{15}$ Measurement error in exposure indicator was included to account for different macroeconomic indicators, which have been used to capture the financial crisis, the main focus of our review. The tool is presented in table 1 , along with the definition of each domain.

Studies were given a rating for each domain, with each scored as 1 (strong; low risk of bias), 2 (moderate; moderate risk of bias), or 3 (weak; high risk of bias). An overall rating for each study was based on the rating of each domain. A study was given an overall rating of 1 (strong) if none of its domains was rated as weak; 2 (moderate) if up to two domains were rated as weak; and 3 (weak) if three or more domains were rated as weak. Each study was assessed independently by two authors. We compared the rating for each domain, as well as the overall rating, and reached a consensus on the final rating for each included study. We calculated the weighted $\kappa$ for each domain as well as for the overall rating.

\section{Patient involvement}

No patients were involved in setting the research question or the outcome measures, nor were they involved in developing plans for design, or implementation of the study. No patients were asked to advise on interpretation or writing up of results. There are no plans to disseminate the results of the research to study participants or the relevant patient community.

\section{Results}

Figure 1 shows the results of the review process. We screened 4801 studies by title and abstract for possible inclusion. The full texts of 108 studies were assessed for eligibility. In total, 41 studies ${ }^{16-56}$ met our selection criteria and were included in the systematic review.

Table B in the supplementary appendix presents the data extraction of the papers that were included in the review. The vast majority of the papers focused on

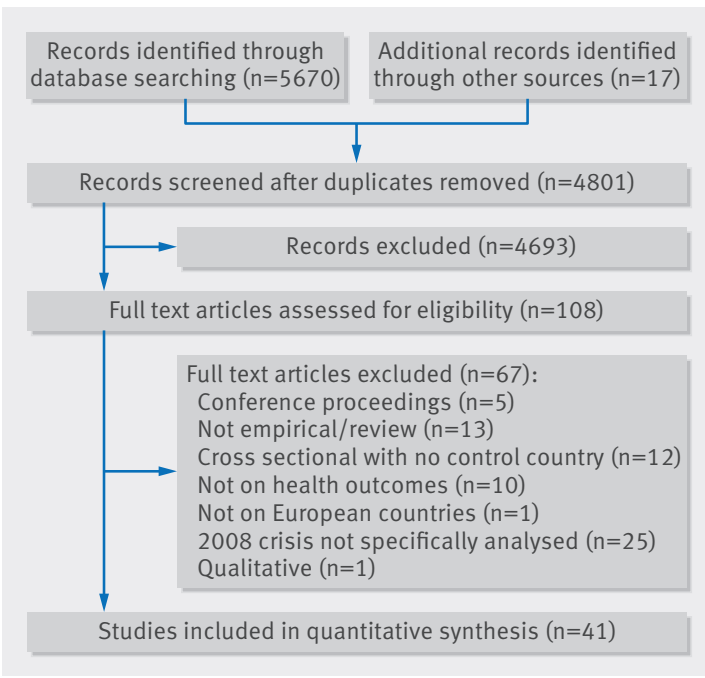

Fig 1 | PRISMA flow diagram of papers reporting on health outcomes during the financial crisis in Europe, published from January 2008 to December 2015 
Spain $(n=10)$ and Greece $(n=9)$. Other countries included the UK and its four constituencies $(n=7)$, Ireland $(n=1)$, Italy $(n=1)$, Iceland $(n=2)$, and France $(n=1)$. Ten papers used data from more than one country, either to collectively analyse the data or to compare outcomes across countries. The health outcomes that the papers studied included suicide $(\mathrm{n}=16)$, mental health $(n=14)$, self rated health $(n=12)$, mortality $(n=2)$, and other health outcomes $(n=9)$. Some papers studied more than one health outcome. The studies are summarised in table 2 .

\section{Risk of bias assessment}

Of the 41 studies we reviewed, $30(73 \%)$ were rated as weak, showing a high risk for bias in at least three domains. Nine studies (22\%) were rated as moderate, showing a high risk for bias in up to two domains (table 3). Only two studies (5\%) were rated strong in the overall risk assessment. The weighted $\kappa$ for each domain and the overall rating are also presented in table 3. Nearly half $(n=20)$ of the studies had a high risk of ecological fallacy, because they made inferences about individual characteristics based on aggregate level data. Time bias was also a common concern (none of the studies had a low risk of time bias). Most studies used data covering periods shorter than 10 years, considered fewer than three years of data after the crisis, and did not account for potential lag effects. Many studies were also at a high risk of reporting bias (54\%), measurement bias in exposures (44\%), and measurement bias in health outcome (56\%). In particular, almost all studies on suicides (14 of 16 studies) and mortality (both), were rated as weak (that is, had a high risk of bias).

\section{Suicides}

Most of the 16 relevant studies reported a significant increase in suicides during the financial crisis and found that men-particularly those of working age and the unemployed-were more significantly affected, while suicide rates among women were largely unaffected.

Four Greek studies used data from the Hellenic Statistical Authority (ELSTAT) but applied different analyses. Using interrupted time series analysis from 1983 to 2012, Branas and colleagues ${ }^{23}$ found that total and male suicides increased in June 2011 by $35.7 \%$ $(\mathrm{P}<0.001)$ and $18 \%(\mathrm{P}<0.01)$, respectively, and female suicides increased by $35.8 \%(\mathrm{P}<0.05)$ in May 2011. Kontaxakis and colleagues ${ }^{41}$ used data from 2001-11 and compared the specific suicide rate in 2008-11 with that in 2001-07. They found that overall specific suicide rate increased (from a negative rate of $-3.9 \%$ to a positive rate of $+27.2 \%$ ), and the rate for men increased (from $-8.4 \%$ to $+26.9 \%, \mathrm{P}<0.05$ ), especially for men aged 30-54 years, and decreased for men aged 60-64 years. For women, no statistically significant change was observed. Madianos and colleagues ${ }^{44}$ using 1990-2011 data, found that age adjusted suicide rates increased by 19\% between 2005 and 2011. Rachiotis and colleagues ${ }^{46}$ used ELSTAT data for 2003-12 and correlation and regression analyses, and found that overall suicide rates increased 35\% between 2010 and 2012; rates increased for both sexes. Comparing 2003-10 with 201112 , the researchers found that suicides increased by $29 \%$ for men $(\mathrm{P}<0.01)$ and $33 \%$ for women $(\mathrm{P}=0.03)$. Unemployment in 2003-12 was associated with suicides for working aged men but not for working aged women.

A fifth study by Antonakakis and Collins ${ }^{17}$ used data on suicides from the WHO Mortality Database for the years 1968-2009, figures from a published paper for 2010, and figures from a Greek newspaper for 2011. They found a significant age and sex specificity. For men, austerity measures and negative economic growth significantly increased suicide rates. Unemployment increased suicide rates for men aged 25-44 years only, while for women no association was found with austerity measures and economic growth. Unlike men, unemployment was in fact associated with reducing suicide rates for all age groups in women.

In Spain, Cordoba-Dona and colleagues ${ }^{27}$ found an increase in suicide attempt rates for both sexes during 2008-12 in Andalucía. They found a significant association between suicide attempts and unemployment for men but not for women. Another Spanish study, ${ }^{43}$ using monthly suicide rates by region and age group and population data from Spain's National Statistics Institute for 2005-10, found an $8 \%$ increase in the suicide rate $(\mathrm{P}=0.03)$ during the crisis. Suicides increased by $9 \%$ in the Mediterranean region and by 19\% among men. Results for women and for other regions were non-significant.

In Ireland, an interrupted series analysis using data from the Irish Central Statistics Office found that, by the end of 2012, the male suicide rate was 57\% higher (that is, 476 more suicides) than if the pre-crisis trend had continued. ${ }^{25}$ Those most affected were men aged 25-44 years. Female suicide rates were unchanged.

In England, Barr and colleagues ${ }^{20}$ were first to show an increase of suicides after 2008. Between 2008 and 2010, they reported 846 more male suicides and 155 more female suicides than would have been expected based on previous trends. They also showed links between suicide trends and unemployment, By contrast, Coope and colleagues ${ }^{26}$ found no change in overall male suicides in England and Wales. They documented a halt in the previous downward trend in suicide rates for men aged 16-34 years in 2006 and an upward trend in early 2010 for those aged 35-44 years. For women, there was no change in suicide rates. Another study found no change in suicides rates in England after 2008 for both men and women, with potential heterogeneity across regions. ${ }^{52}$

Six studies provided comparative results across several countries. Laanani and colleagues ${ }^{42}$ used data for 2000-10 from eight countries and found a 3.3\% increase in the overall suicide rate during the crisis. Associations between unemployment rate and suicide rate were significant in three countries: $0.7 \%$ (95\% confidence interval $0.0 \%$ to $1.4 \%)$ in the Netherlands, $1.0 \%(0.2 \%$ to $1.8 \%$ ) in the UK, and $1.9 \%$ (0.8\% to $2.9 \%$ ) in France. They estimated that unemployment accounted for 564 


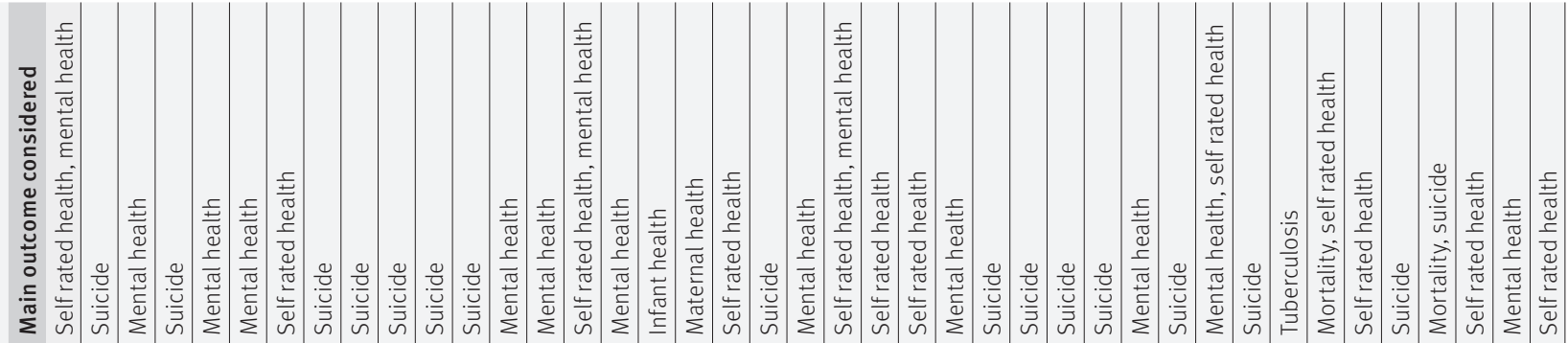

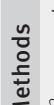

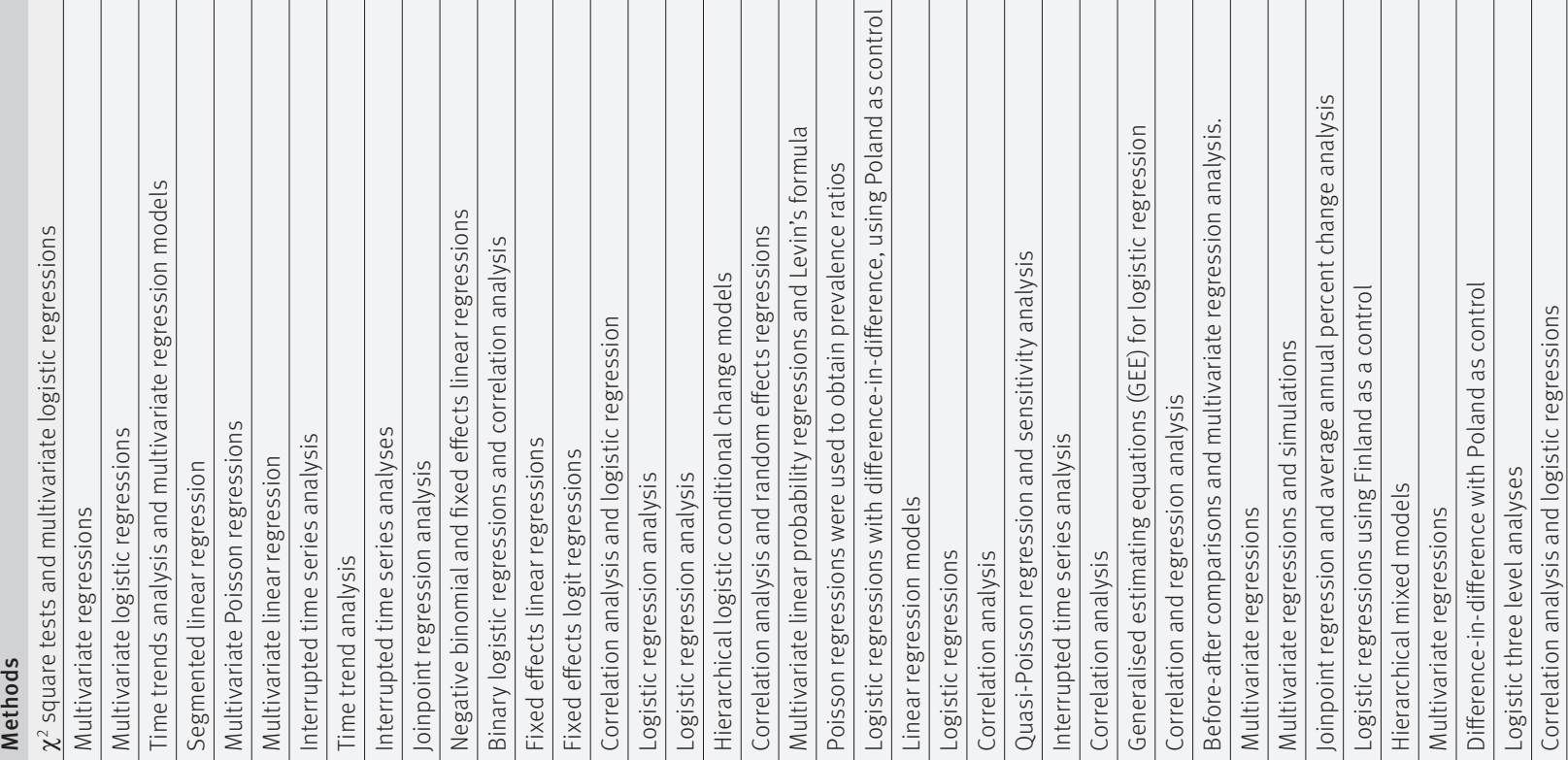

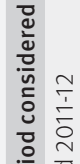

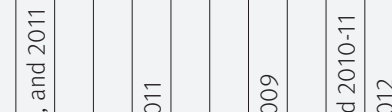

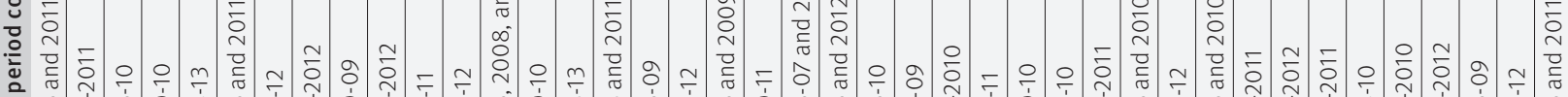

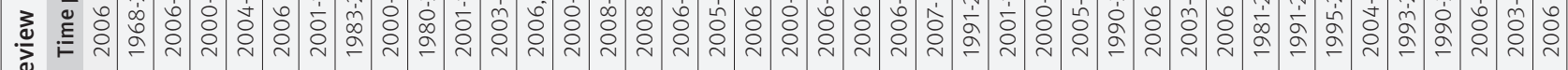

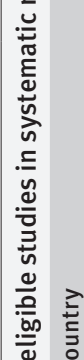
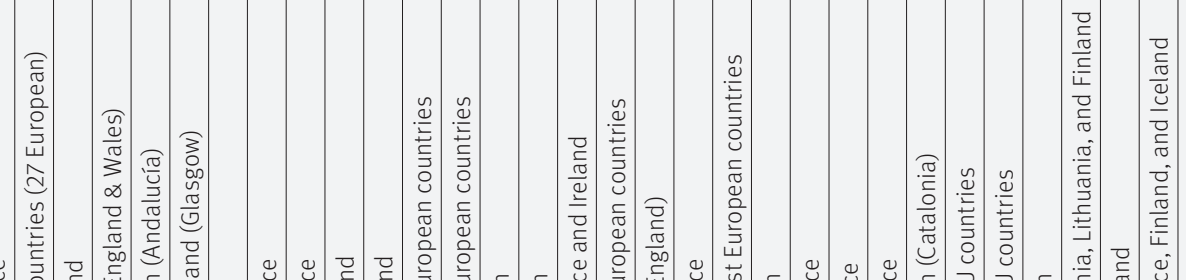

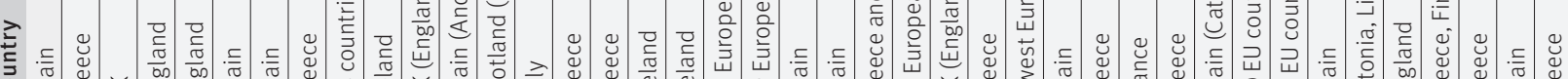

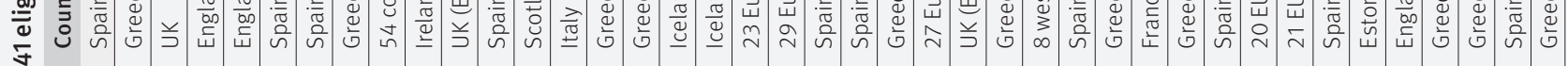

$\frac{1}{0}$

$\frac{u}{4}$

旁

辛

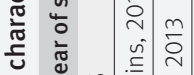

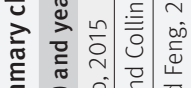

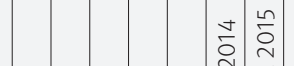

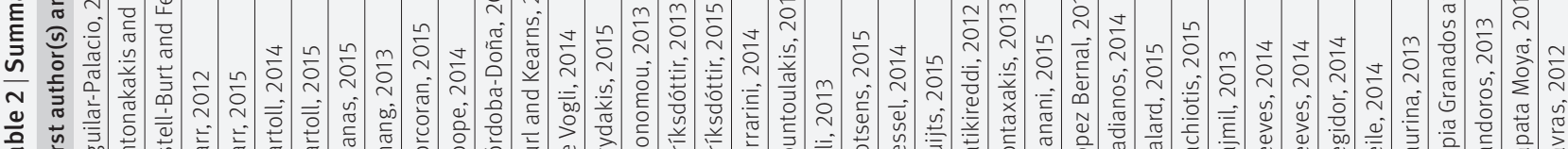

$\stackrel{n}{\check{c}}$

บ

는 
Table 3 | Assessment of risk of bias for 41 eligible studies included in systematic review

\begin{tabular}{|c|c|c|c|c|c|c|c|c|}
\hline Paper (first author(s), year) & $\begin{array}{l}\text { Selection } \\
\text { bias }\end{array}$ & $\begin{array}{l}\text { Ecological } \\
\text { fallacy }\end{array}$ & $\begin{array}{l}\text { Confounding } \\
\text { bias }\end{array}$ & $\begin{array}{l}\text { Reporting } \\
\text { bias }\end{array}$ & $\begin{array}{l}\text { Time } \\
\text { bias }\end{array}$ & $\begin{array}{l}\text { Measurement error } \\
\text { in exposure variable }\end{array}$ & $\begin{array}{l}\text { Measurement } \\
\text { error in health } \\
\text { outcome }\end{array}$ & $\begin{array}{l}\text { Overall } \\
\text { rating }\end{array}$ \\
\hline Aguilar-Palacio, 2015 & 3 & 1 & 2 & 3 & 3 & 2 & 3 & 3 \\
\hline Antonakakis and Collins, 2014 & 2 & 3 & 2 & 2 & 3 & 1 & 3 & 3 \\
\hline Astell-Burt and Feng, 2013 & 3 & 1 & 2 & 3 & 3 & 3 & 3 & 3 \\
\hline Barr, 2012 & 1 & 3 & 2 & 1 & 2 & 2 & 3 & 2 \\
\hline Barr, 2015 & 3 & 1 & 3 & 3 & 3 & 2 & 3 & 3 \\
\hline Bartoll, 2014 & 3 & 1 & 2 & 2 & 3 & 3 & 2 & 3 \\
\hline Bartoll, 2015 & 2 & 1 & 2 & 3 & 2 & 2 & 2 & 2 \\
\hline Branas, 2015 & 1 & 3 & 3 & 2 & 2 & 3 & 3 & 3 \\
\hline Chang, 2013 & 2 & 3 & 2 & 1 & 3 & 3 & 3 & 3 \\
\hline Coope, 2014 & 2 & 3 & 2 & 3 & 2 & 1 & 3 & 3 \\
\hline Corcoran, 2015 & 1 & 3 & 2 & 2 & 2 & 3 & 3 & 3 \\
\hline Córdoba-Doña, 2014 & 3 & 3 & 2 & 2 & 2 & 2 & 2 & 2 \\
\hline Curl and Kearns, 2015 & 3 & 1 & 3 & 3 & 2 & 2 & 2 & 3 \\
\hline De Vogli, 2014 & 1 & 3 & 3 & 3 & 2 & 1 & 3 & 3 \\
\hline Drydakis 2015 & 2 & 1 & 2 & 2 & 2 & 2 & 2 & 1 \\
\hline Economou, 2013 & 2 & 1 & 1 & 3 & 3 & 3 & 2 & 3 \\
\hline Eiríksdóttir, 2013 & 1 & 1 & 2 & 3 & 3 & 3 & 1 & 3 \\
\hline Eiríksdóttir, 2015 & 1 & 1 & 2 & 2 & 2 & 2 & 2 & 1 \\
\hline Ferrarini, 2014 & 2 & 3 & 2 & 3 & 3 & 3 & 3 & 3 \\
\hline Fountoulakis, 2014 & 2 & 3 & 3 & 3 & 2 & 1 & 3 & 3 \\
\hline Gili, 2013 & 2 & 1 & 2 & 3 & 3 & 1 & 2 & 2 \\
\hline Gotsens, 2015 & 3 & 1 & 2 & 3 & 3 & 3 & 2 & 3 \\
\hline Hessel, 2014 & 3 & 1 & 1 & 2 & 3 & 3 & 2 & 3 \\
\hline Huijts, 2015 & 1 & 1 & 1 & 2 & 3 & 2 & 2 & 2 \\
\hline Katikireddi, 2012 & 2 & 1 & 1 & 2 & 2 & 2 & 2 & 2 \\
\hline Kontaxakis, 2013 & 1 & 3 & 3 & 3 & 2 & 3 & 3 & 3 \\
\hline Laanani, 2015 & 3 & 3 & 1 & 3 & 2 & 2 & 3 & 3 \\
\hline Lopez Bernal, 2013 & 2 & 3 & 2 & 2 & 3 & 3 & 3 & 3 \\
\hline Madianos, 2014 & 1 & 3 & 3 & 3 & 2 & 1 & 3 & 3 \\
\hline Malard, 2015 & 2 & 1 & 2 & 1 & 3 & 3 & 2 & 3 \\
\hline Rachiotis, 2015 & 2 & 3 & 2 & 3 & 2 & 2 & 3 & 3 \\
\hline Rajmil, 2013 & 3 & 1 & 2 & 3 & 3 & 2 & 2 & 3 \\
\hline Reeves (20 EU countries), 2014 & 2 & 3 & 2 & 3 & 2 & 2 & 3 & 3 \\
\hline Reeves (21 EU countries), 2014 & 2 & 3 & 2 & 2 & 2 & 1 & 3 & 2 \\
\hline Regidor, 2014 & 2 & 3 & 3 & 3 & 2 & 3 & 1 & 3 \\
\hline Reile, 2014 & 3 & 1 & 2 & 2 & 3 & 3 & 3 & 3 \\
\hline Saurina, 2013 & 1 & 3 & 3 & 3 & 2 & 2 & 3 & 3 \\
\hline Tapia Granados and Rodriguez, 2015 & 1 & 3 & 3 & 3 & 2 & 3 & 3 & 3 \\
\hline Vandoros, 2013 & 3 & 1 & 1 & 1 & 3 & 3 & 3 & 3 \\
\hline Zapata Moya, 2015 & 3 & 1 & 2 & 2 & 2 & 3 & 2 & 2 \\
\hline Zavras, 2012 & 3 & 1 & 1 & 2 & 3 & 2 & 2 & 2 \\
\hline Weighted $\kappa$ & 0.65 & 0.83 & 0.64 & 0.56 & 0.70 & 0.6059 & 0.75 & 0.76 \\
\hline
\end{tabular}

additional suicides in France, 57 in the Netherlands, and 456 in the UK. They found no associations in Austria, Finland, Spain, and Sweden. Comparing suicide rates between 2003-07 and 2008-12 in Greece, Iceland, and Finland, Tapia Granados and Rodriguez ${ }^{53}$ found an increase in suicides in 2008-12 for Greece only, although they reported that even at its peak in 2011, this rate remained low-a third of the mean suicide rate in the EU.

Using 2000-09 WHO mortality data for 27 European countries, Chang and colleagues ${ }^{24}$ found 2937 additional male suicides in 2009 over the previous pre-crisis trend. The highest increase was among the male age group 15-24 years, while suicide rates for women remained stable. Another study on 29 European countries during 2000-11 found a strong correlation between male suicide rates and all economic indices except for
GDP per capita, and a correlation between female suicides and unemployment only. ${ }^{35}$ The researchers found that the temporal relation did not support causality (suicide rates increased several months before the crisis emerged). Reeves and colleagues ${ }^{48}$ used data on male suicides from 20 EU countries (1981-2011) and estimated 6998 excess suicides after 2008 , based on pre-crisis suicide trends. Of these, 1077 (15\%) were attributed to increased unemployment. Further, they estimated that spending on active labour market programmes prevented $540(50 \%)$ suicides, and high levels of social capital prevented another 210 (19\%).

\section{Mental health}

Most, but not all, of the 14 relevant studies found an association between deteriorating economic indicators and poor mental health, particularly among men. 
In Italy, De Vogli and colleagues ${ }^{29}$ found that the crisis resulted in an additional 548 deaths due to mental and behavioural disorders (that is, 0.303 per 100000 deaths per year). Further, they estimated that $22.4 \%$ of these deaths could be attributed to income loss and $16.4 \%$ to unemployment.

In Greece, using longitudinal telephone surveys, Drydakis $^{30}$ found that unemployment was associated more with poor mental health in 2010-13 than in 2008-09. Among women, unemployment increased poor mental health from $4.3 \%$ to $7.3 \%$ and, among men, from $3 \%$ to $4.9 \%(\mathrm{P}<0.001)$. Another Greek study that found the odds of a person having major depression was 2.6 times greater in 2011 than in 2008. ${ }^{31}$

In Spain, four studies used data from the Spanish National Health Surveys (2006 and 2011-12). Among young people (16-24 years), Aguilar-Palacio and colleagues $^{16}$ found that the prevalence of poor mental health decreased for women in 2012 versus 2006, with no change for men. However, they identified unemployment ( $>1$ year) as a risk factor for poor mental health in 2012 for men. Bartoll and colleagues ${ }^{22}$ also found reduced prevalence of poor mental health among young women (prevalence ratio $0.89, \mathrm{P}<0.001$ ), with no change for men. For the older population, they found that the prevalence of poor mental health increased among men with no change among women over age 25 years. Comparing immigrants with natives, Gotsens and colleagues $^{37}$ reported a new onset of inequalities in poor mental health between immigrants and native men and an equalisation of the previously lower use of psychotropic drugs by male immigrants, with no change for female immigrants. Finally, Zapata Moya and colleagues ${ }^{55}$ reported that depression increased by $12 \%$ in $2009(\mathrm{P}<0.05)$ and by 23\% in $2011(\mathrm{P}<0.001)$ among women, and by $13 \%$ in $2011(\mathrm{P}<0.10)$ among men compared with 2003. These effects disappeared after controlling for changes in GDP growth rate.

Of the two remaining studies on Spain, Gili and colleagues $^{36}$ found that unemployment was associated with major depressive disorders in both 2006 and 2010 (odds ratio 1.54 and 1.72, respectively; $\mathrm{P}<0.001$ ) among primary healthcare attendees. In 2010, the association between unemployment and minor depressive disorders increased $(1.20 ; \mathrm{P}<0.001)$, while for dysthymia, there was no association. One third of major depression in 2012 was attributed to individual and family unemployment and mortgage payment difficulties. Lastly, Rajmil and colleagues ${ }^{47}$ studied children in Catalonia, and reported no changes in 2010-12 versus 2006 and no association between children's mental health and parental employment status.

In France, using a prospective national survey, Malard and colleagues ${ }^{45}$ found no change in the prevalence of major depressive episodes and generalised anxiety disorder for both sexes in the working population-except for an increase of $7.4 \%(\mathrm{P}=0.007)$ in the disorder among women working in the public sector. Astell-Burt and Feng, ${ }^{18}$ using population data from the Quarterly Labour Force Survey in the UK, found a 0.2\% increase in depression and $0.1 \%$ increase in mental ill- ness during the crisis. Curl and Kearns ${ }^{28}$ examined the effect of financial difficulties on mental health in deprived areas of Glasgow and found that decreased affordability was associated with declining mental health. Katikireddi and colleagues, ${ }^{40}$ using repeated cross sectional surveys in England, found that prevalence of poor mental health in men increased after 2008 (by 5\% in 2009 and by 3\% in 2010), but the men's changing employment status did not explain this increase. The same study showed no change in poor mental health prevalence among women. Barr and colleagues ${ }^{19}$ found that, although mental health problems increased post-crisis $(+0.08 \%$ prevalence per quarter), only $36 \%$ of the additional problems could be explained by rising unemployment and declining wages.

\section{Self rated health}

Twelve studies focused on the impact of the crisis on self rated health, finding mixed results depending on the country and group analysed. Three studies on Spain, analysing data from the Spanish National Health Survey, found an improvement in self rated health during the crisis. Aguilar-Palacio and colleagues ${ }^{16}$ found that people aged 16-24 years had better self rated health in 2012 than in 2006, and this is more evident among women. They found no association between unemployment and self rated health, but students of both sexes had lower risk of poor self rated health than workers did. Bartoll and colleagues ${ }^{21}$ showed that the probability of good self rated health increased for by $7.6 \%(\mathrm{P}<0.01)$ for men and by $9.6 \%(\mathrm{P}<0.01)$ for women in 2011-12 versus 2001. Regidor and colleagues ${ }^{50}$ found that the prevalence of poor self rated health fell during the financial crisis by $5.7 \%$. A fourth Spanish study using data from the same survey ${ }^{37}$ found that immigrants who arrived before 2006 had worse self rated health than natives. For women, inequalities in poor self rated health between immigrants and natives increased.

A study on Catalonia ${ }^{47}$ observed an improvement in health related quality of life, but children whose mothers had only a primary education had poorer scores for health related quality of life in 2010-12 than in 2006.

In Greece, Zavras and colleagues ${ }^{56}$ found that the overall prevalence of good and very good self rated health in 2006 was $71 \%$, whereas in 2011, the prevalence decreased to $69 \%(\mathrm{P}<0.05)$, with unemployed people less likely to report good health. Another study using a different cross sectional survey found that unemployment was associated with poor self rated health, and women were more affected than men. ${ }^{30} \mathrm{~A}$ difference-in-difference study comparing Greece with Ireland, using Poland as a control, found an increase in the prevalence of poor self rated health in Greece but not in Ireland in 2010. ${ }^{38}$ A similar study comparing Greece to Poland found an increase in poor self rated health in Greece after the crisis. ${ }^{54}$

Three comparative studies found evidence of a negative impact of the crisis on self rated health. Comparing Estonia, Lithuania, and Finland, Reile and colleagues. ${ }^{51}$ found that during 2008-10, the prevalence of poor self 
rated health increased from $50 \%$ to $52 \%$ in Estonia and from $47 \%$ to $48 \%$ (from 47\%) in Lithuania. The increase was not statistically significant, but marked the end of the previous positive trend of improving health status. Studying 23 European countries, Ferrarini and colleagues ${ }^{34}$ found that unemployment insurance reduced the transition to deteriorating self rated health during the crisis. Huijts and colleagues ${ }^{39}$ examined the impact $^{-}$ of job loss and recovery on self rated health in 27 European countries. Job loss during the crisis was negatively associated with self rated health for both women and men. Job recovery within a year led to health recovery for women, while men had an enduring health disadvantage.

\section{Mortality}

Of the two studies on mortality rates, Regidor and colleagues, ${ }^{50}$ using 1995-2011 national registry data from Spain, found that premature mortality rates from several causes fell during the crisis. Overall mortality in 2008-11 dropped by $2.5 \%$ (cardiovascular diseases 5.6\%, respiratory diseases $2.8 \%$, digestive diseases $2.8 \%$, genitourinary diseases $7 \%$, HIV 6.8\%, other infectious diseases $8.7 \%$, road accidents $14.2 \%$, other unintentional injuries 3.8\%, suicides $1.3 \%$, homicides $6.9 \%$, cancer mortality remained constant). Tapia-Granados and Rodriguez ${ }^{53}$ analysed WHO data on Iceland, Finland, and Greece for 1990-2012 and concluded that the crisis had no impact on mortality, as mortality dropped faster or continued falling after 2007 as quickly as in previous years, for almost all age groups. Comparisons between Greece and the other two countries showed no significant differences in most mortality indicators.

\section{Other health outcomes}

Nine studies, examining other health outcomes, found mixed results. Eiriksdottir and colleagues, ${ }^{32}$ studying infant health in Iceland, found increased odds of low birthweight deliveries after the crisis (from 2.5\% to 3\%), particularly among mothers younger than 25 years and among unemployed mothers. After controlling for age, parity, and seasonality, the increase was significant (adjusted odds ratio 1.25, 95\% confidence interval 1.02 to 1.53 ), but the association disappeared after controlling for other variables (sex, diabetes, hypertension, relationship status, place of residency, and employment status). There was no significant change in small-for-gestational-age and preterm births. In another Icelandic study, prevalence of pregnancy induced hypertensive disorders increased in the first year following the economic collapse $(2.4 \% v 3.9 \%$; adjusted odds ratio 1.47 ; $95 \%$ confidence interval 1.13 to 1.91 ) but not in subsequent years. ${ }^{33}$ The association disappeared after controlling for unemployment.

Comparing Greece, Finland, and Iceland, a study found no effect on the incidence of tuberculosis and HIV during the crisis, which continued to drop. ${ }^{53}$ Regidor and colleagues ${ }^{50}$ found the same for HIV incidence in Spain ( $1 \%$ decrease, not significant). Gotsens and colleagues $^{37}$ and Rajmil, ${ }^{47}$ when controlling for unemployment, also found no significant changes in Spain regarding chronic activity limitation among immigrant women and child obesity. Zapata Moya and colleagues 55 presented mixed results in Spain, showing that in 2011, compared with 2006, diabetes increased among in both sexes, but the effect was non-significant when controlling for real GDP growth rate and low work intensity indicator. The study also found a marginal decrease in myocardial infarction for men and malignant tumours in women during the same period, but this effect was non-significant after controlling for the macroeconomic context. Astell-Burt and Feng ${ }^{18}$ reported an increased prevalence of cardiovascular $(0.6 \%)$ and respiratory problems (1\%) in the UK in 2010 versus 2008. Reeves and colleagues ${ }^{49}$ combined data for $21 \mathrm{EU}$ countries from 1991-2012 and concluded that during 2007-12, there was no significant association between social protection spending and tuberculosis case detection $(-0.59 \%$ reduction in case detection for a US\$100 ( $€ 75.9$; €88.3) increase in social protection spending, 95\% confidence interval -1.31 to 0.14 ).

\section{Discussion}

\section{Principal findings}

The amount of evidence on the impact of the financial crisis on health outcomes in Europe is growing. Of the 41 studies that met our criteria and were analysed, the vast majority focused on two countries in the south: Spain and Greece. The main health outcomes that these studies explored were suicides and mental health.

We found that most of the studies had a substantial risk of bias and, therefore, we should be cautious with the interpretation of the results. There were only two studies that were rated as having a low risk of bias. The study by Drydakis ${ }^{30}$ found that self rated health and mental health deteriorated among unemployed people versus employed people in Greece, and the study by Eiriksdottir ${ }^{33}$ found only a temporary increase in the prevalence of hypertension among pregnant women in Iceland, but not in subsequent years.

Using the risk assessment tool we developed, we found several aspects in which the current evidence fell short of providing robust evidence on the health effects of the crisis. Earlier studies were inevitably constrained by data availability; many mortality and suicide studies used data from only one or two years into the crisis. Many studies did not adjust for pre-existing trends, for example, mortality rates were falling before the start of the crisis. There were issues with the design of some studies, such as those on self rated health that used cross sectional data and therefore had difficulties establishing temporality, let alone causality.

The cautious conclusions that we can draw from the studies we analysed, is that the effect of the crisis was different across and within countries. Most studies on suicides showed an increase in suicides during the financial crisis, in particular among men. Studies looking at mental health found similar increases, but these results were more mixed. Studies focusing on mortality seemed to show a different picture, with overall mortality not being affected or even declining during the crisis years. It has been argued that this was probably due to 
fewer working hours ${ }^{50}$ and healthier lifestyles during years of economic difficulties. ${ }^{16}$ Some claim that factors other than the crisis-such as improvements in road safety policies and a declining prevalence of injectable drug use, ${ }^{50}$ explain these findings.

Our main finding of mixed effects on health outcomes accords with most previous literature on financial crises and health. ${ }^{57}$ An empirical study conducted before the crisis $^{58}$ on data from 26 European countries (1970-2007) showed that unemployment was positively associated with suicide rates and homicides and negatively associated with deaths due to road accidents. Data from the USA also suggest that overall mortality is procyclical and decreases during financial crises, while suicides are countercyclical and increase when the economy worsens. ${ }^{15}$

Our findings shed some light on the groups most affected during the financial crisis. The results on sex and age were somehow contradictory, but, overall, men of working age seemed to be more severely affected, as reflected mainly in suicide trends and self rated health. In terms of mental health, however, women seemed to have performed worse than men. There is also some evidence that the health of immigrants, especially those who had illegal status and lacked social security, deteriorated much more during the crisis than that of natives. This is consistent with previous studies that showed worse effects on groups that lack social protection. ${ }^{58}$ Finally, some evidence suggests that the crisis increased social inequalities in health, disproportionately affecting immigrants, ${ }^{37}$ those who were less educated, and those living in certain regions. ${ }^{52}$

Further, from a policy perspective, most studies failed to capture the mechanisms that affect health outcomes. In addition, studies that used year dummies to capture the impact of the financial crisis or that had split the data into pre-crisis and post-crisis periods were not informative as to whether the effect was due to reductions in government spending, increased household financial constraints, or both. Finally, observed age and sex differences should be interpreted cautiously because these were subgroup analyses, and it is difficult to know whether the subgroups were prespecified.

\section{Strengths and limitations of study}

A major limitation of this review is that it inevitably explored relatively short term effects of the crisis on health outcomes. It may take some years before the full consequences of the financial crisis are observed. ${ }^{59}$ Moreover, reporting bias can be an issue not only for single studies, but also for the field at large. Publication bias could result in significant associations being preferentially published, which might be an even greater issue for secondary exploratory analyses of factors or subgroups associated with different health outcomes. Furthermore, depending on what investigators believe about topics that are socially and politically sensitive, the published evidence may be affected by allegiance and confirmation biases.

We also focused only on English language papers and those that were published in full text. As a robustness check, we looked at studies that were published in Greek, Spanish, Italian, and Portuguese (113 studies) that were excluded from our analysis on the basis of language, only to confirm that these papers did not meet our other selection criteria. Proceedings abstracts could also contain some useful information, but their quality is less certain, and it is possible that allegiance biases might be even stronger in some of them. Although we excluded qualitative studies, we came across only one study that would have met our other selection criteria. This study by Ronda and colleagues ${ }^{60}$ focused on immigrants in Spain, and concluded that the quality of life and self rated health of immigrants deteriorated during the crisis, but this does not change much the conclusiveness of the available evidence. Finally, measurement error could be substantial for some of the examined crisis indicators and health outcomes. In particular, suicides could have been under-recorded and misreported in death certificates for social or religious reasons in some countries, such as Greece. It is unknown whether the crisis affected the extent of this potential bias.

Despite its limitations, this is the first systematic review of the literature on the effect of the 2008 financial crisis in Europe on health outcomes, which also assesses the risk of bias of the reviewed studies. We believe that our emphasis on the assessment of risk of bias, can be influential for a wider range of studies looking at the effects of economic, environmental, and societal factors on health, such as the impact of climate change on health ${ }^{61}$ and of alcohol pricing and consumption. ${ }^{62}$ Currently, the availability of risk assessment tools for these types of studies are limited.

\section{Future research}

A review of the impact of the crisis on health behaviours, such as smoking and alcohol consumption, which was beyond the scope of this review, would have shed light on the links between changes in habits and health outcomes. From a first glance, the evidence seems mixed, with some favourable trends in smoking prevalence (eg, McClure and colleagues'study ${ }^{63}$ for Iceland; Filippidis and colleagues' study ${ }^{64}$ in Greece) and some more worrying results regarding vegetable consumption (Filippidis and colleagues ${ }^{64}$ ). Finally, our study, by focusing on health outcomes exclusively, did not look at the impact of the crisis on health systems, such as shortages in health workforce and medical supplies, where several studies have shown a negative trend during the financial crisis. ${ }^{6566}$ A review of this literature was beyond the scope of this study and it is left for future research.

\section{Conclusions}

The evidence on the impact of the financial crisis on health outcomes in Europe is mixed, and the data and methodologies used in many papers are susceptible to substantial bias. We need more empirical studies that explore the impact of the crisis on health and, more importantly, investigate the mechanisms that affect health outcomes. As more data becomes available, it is also possible to consider the potential lag effects of the 
crisis, a clear limitation of most studies so far. Better quality data are needed and governments should make accurate data on health outcomes available as quickly as they seem to do for economic indicators.

We thank Maria Raisa Jessica Aquino for helping with the initial literature search.

Contributors: DP and CS were involved in the initial conception and design of the study. DP secured funding. DP and CS developed the search strategy and extracted data from included studies. DP and CS were involved in the data analysis. DP. CS, and IPAI developed the assessment of risk of bias tool. DP, CS, and IPAI were involved in the interpretation and discussion of results. CS developed the first draft of the manuscript and all authors critically revised it and approved the final version. DP and CS are co-first authors and study guarantors. Maria Raisa Jessica Aquino contributed to the initial literature search as a non-author.

Funding: The study was financially supported by a pump priming scheme from the School of Health Sciences at City University London. The funder was not involved in the research and preparation of the article, including study design; collection, analysis, and interpretation of data; writing of the article; nor in the decision to submit it for publication. Competing interests: All authors have completed the ICMJE uniform disclosure form at www.icmje.org/coi_disclosure.pdf (available on request from the corresponding author) and declare: the study was financially supported by a pump priming scheme from the School of Health Sciences at City University London; no financial relationships with any organisations that might have an interest in the submitted work in the previous three years; no other relationships or activities that could appear to have influenced the submitted work.

Ethical approval: Not required.

Data sharing: No additional data available.

The lead authors affirm that this manuscript is an honest, accurate, and transparent account of the study being reported; that no important aspects of the study have been omitted; and that any discrepancies from the study as planned (and, if relevant, registered) have been explained.

This is an Open Access article distributed in accordance with the Creative Commons Attribution Non Commercial (CC BY-NC 3.0) license, which permits others to distribute, remix, adapt, build upon this work non-commercially, and license their derivative works on different terms, provided the original work is properly cited and the use is noncommercial. See: http://creativecommons.org/licenses/by-nc/3.0/.

1 Cylus J, Pearson M. The crisis and its implications for household financial security, government resources and health expenditure. In: Thomson S, Figueras J, Evetovits T, et al, eds. Economic crisis, health systems and health in Europe: impact and implications for policy.Open University Press, 2015

2 Quaglio G, Karapiperis T, Van Woensel L, Arnold E, McDaid D. Austerity and health in Europe. Health Policy 2013;113:13-9. doi:10.1016/j. healthpol.2013.09.005.

3 Kentikelenis A, Karanikolos M, Papanicolas I, Basu S, McKee M, Stuckler D. Health effects of financial crisis: omens of a Greek tragedy. Lancet 2011:378:1457-8 doi:10.1016/S0140-6736(11)61556-0.

4 Karanikolos M, Mladovsky P, Cylus J, et al. Financial crisis, austerity, and health in Europe. Lancet 2013;381:1323-31. doi:10.1016 S0140-6736(13)60102-6.

5 Stuckler D, Basu S, Suhrcke M, Coutts A, McKee M. The public health effect of economic crises and alternative policy responses in Europe: an empirical analysis. Lancet 2009;374:315-23. doi:10.1016/ S0140-6736(09)61124-7.

6 Tapia Granados JA, Diez Roux AV. Life and death during the Great Depression. Proc Natl Acad Sci U S A 2009;106:17290-5. doi:10.1073/ pnas.0904491106.

7 Brainerd E, Cutler DM. Autopsy on an empire: understanding mortality in Russia and the former Soviet Union. J Econ Perspect 2005;19:107-30doi:10.1257/0895330053147921.

8 Simou E, Koutsogeorgou E. Effects of the economic crisis on health and healthcare in Greece in the literature from 2009 to 2013: a systematic review. Health Policy 2014;115:111-9. doi:10.1016/j. healthpol.2014.02.002.

9 Van Hal G. The true cost of the economic crisis on psychological well-being: a review. Psychol Res Behav Manag 2015;8:17-25. doi:10.2147/PRBM.S44732.

10 Rajmil L, Fernandez de Sanmamed MJ, Choonara I, et al. International Network for Research in Inequalities in Child Health (INRICH). Impact of the 2008 economic and financial crisis on child health: a systematic review. Int J Environ Res Public Health 2014;11:6528-46. doi:10.3390/ijerph110606528
11 Centre for Reviews and Dissemination. Systematic reviews. York Publishing Services, 2009

12 Moher D, Liberati A, TetzlaffJ, Altman DG. PRISMA Group. Preferred reporting items for systematic reviews and meta-analyses: the PRISMA statement. PLoS Med 2009;6:e1000097. doi:10.1371/journal. pmed.1000097.

13 Wells G, Shea B, O'connell D, et al. The Newcastle-Ottawa Scale (NOS) for assessing the quality of nonrandomised studies in meta-analyses. www.ohri.ca/programs/clinical_epidemiology/oxford.asp.

14 Viswanathan M, Berkman ND. Development of the RTI item bank on risk of bias and precision of observational studies. J Clin Epidemiol 2012;65:163-78. doi:10.1016/j.jclinepi.2011.05.008

15 Ruhm C. Health effects of economic crisis. National Bureau of Economic Research, 2015; working paper 21604

16 Aguilar-Palacio I, Carrera-Lasfuentes P, Rabanaque MJ. Youth unemployment and economic recession in Spain: influence on health and lifestyles in young people (16-24 years old). Int J Public Health 2015;60:427-35. doi:10.1007/s00038-015-0668-9.

17 Antonakakis N, Collins A. The impact of fiscal austerity on suicide: on the empirics of a modern Greek tragedy. Soc Sci Med 2014;112:39-50. doi:10.1016/j.socscimed.2014.04.019.

18 Astell-Burt T, Feng X. Health and the 2008 economic recession: evidence from the United Kingdom. PLoS One 2013;8:e56674-74. doi:10.1371/journal.pone.0056674.

19 Barr B, Kinderman P, Whitehead M. Trends in mental health inequalities in England during a period of recession, austerity and welfare reform 2004 to 2013. Soc Sci Med 2015:147:324-31. doi:10.1016/j.socscimed.2015.11.009.

20 Barr B, Taylor-Robinson D, Scott-Samuel A, McKee M, Stuckler D. Suicides associated with the 2008-10 economic recession in England: time trend analysis. BMJ 2012;345:e5142. doi:10.1136/bmj.e5142.

21 Bartoll X, Toffolutti V, Malmusi D, Palència L, Borrell C, Suhrcke M. Health and health behaviours before and during the Great Recession, overall and by socioeconomic status, using data from four repeated cross-sectional health surveys in Spain (2001-2012). BMC Public Health 2015:15:865. doi:10.1186/s12889-015-2204-5.

22 Bartoll X, Palència L, Malmusi D, Suhrcke M, Borrell C. The evolution of mental health in Spain during the economic crisis. Eur J Public Health 2014;24:415-8. doi:10.1093/eurpub/ckt208.

23 Branas CC, Kastanaki AE, Michalodimitrakis M, et al. The impact of economic austerity and prosperity events on suicide in Greece: a 30-year interrupted time-series analysis. BMJ Open 2015;5:e005619. doi:10.1136/bmjopen-2014-005619.

24 Chang SS, Stuckler D, Yip P, Gunnell D. Impact of 2008 global economic crisis on suicide: time trend study in 54 countries. BMJ 2013;347:f5239. doi:10.1136/bmj.f5239.

25 Corcoran P, Griffin E, Arensman E, Fitzgerald AP, Perry IJ. Impact of the economic recession and subsequent austerity on suicide and self-harm in Ireland: An interrupted time series analysis. Int J Epidemiol 2015;44:969-77. doi:10.1093/ije/dyv058.

26 Coope C, Gunnell D, Hollingworth W, et al. Suicide and the 2008 economic recession: who is most at risk? Trends in suicide rates in England and Wales 2001-2011. Soc Sci Med 2014;117:76-85. doi:10.1016/i.socscimed.2014.07.024

27 Córdoba-Doña JA, San Sebastián M, Escolar-Pujolar A, Martínez-Faure JE, Gustafsson PE. Economic crisis and suicidal behaviour: the role of unemployment, sex and age in Andalusia, southern Spain. Int J Equity Health 2014;13:55-55. doi:10.1186/1475-9276-13-55.

28 Curl A, Kearns A. Financial difficulty and mental wellbring in an age of austerity: the experience in deprived communities. Soc Policy Soc 2015;14:217-40doi:10.1017/S1474746414000475.

29 De Vogli R, Vieno A, Lenzi M. Mortality due to mental and behavioral disorders associated with the Great Recession (2008-10) in Italy: a time trend analysis. Eur J Public Health 2014:24:419-21. doi:10.1093/ eurpub/ckt173.

30 Drydakis N. The effect of unemployment on self-reported health and mental health in Greece from 2008 to 2013: a longitudinal study before and during the financial crisis. Soc Sci Med 2015;128:43-51. doi:10.1016/j.socscimed.2014.12.025

31 Economou M, Madianos M, Peppou LE, Patelakis A, Stefanis CN. Major depression in the era of economic crisis: a replication of a cross-sectional study across Greece. J Affect Disord 2013;145:308-14 doi:10.1016/j.jad.2012.08.008.

32 Eiríksdóttir VH, Ásgeirsdóttir TL, Bjarnadóttir RI, Kaestner R, Cnattingius S, Valdimarsdóttir UA. Low birth weight, small for gestational age and preterm births before and after the economic collapse in Iceland: a population based cohort study. PLoS One 2013;8:e80499. doi:10.1371/journal.pone.0080499.

33 Eiríksdóttir VH, Valdimarsdóttir UA, Ásgeirsdóttir TL, et al. Pregnancy-induced hypertensive disorders before and after a national economic collapse: a population based cohort study. PLoS One 2015;10:e0138534. doi:10.1371/journal.pone.0138534

34 Ferrarini T, Nelson K, Sjöberg O. Unemployment insurance and deteriorating self-rated health in 23 European countries. J Epidemiol Community Health 2014;68:657-62. doi:10.1136/jech-2013-203721. 
35 Fountoulakis KN, Kawohl W, Theodorakis PN, et al. Relationship of suicide rates to economic variables in Europe: 2000-2011 [correction in: Br J Psychiatry 2015;206:169]. Br J Psychiatry 2014;205:486-96. doi:10.1192/bjp.bp.114.147454

36 Gili M, Roca M, Basu S, McKee M, Stuckler D. The mental health risks of economic crisis in Spain: evidence from primary care centres, 2006 and 2010. Eur J Public Health 2013;23:103-8. doi:10.1093/eurpub/cks035.

37 Gotsens M, Malmusi D, Villarroel N, et al. Health inequality between immigrants and natives in Spain: the loss of the healthy immigrant effect in times of economic crisis. Eur I Public Health 2015;25:923-9. doi:10.1093/eurpub/ckv126.

38 Hessel P, Vandoros S, Avendano M. The differential impact of the financial crisis on health in Ireland and Greece: a quasi-experimental approach. Public Health 2014;128:911-9. doi:10.1016/j.puhe.2014.08.004

39 Huijts T, Reeves A, McKee M, Stuckler D. The impacts of job loss and job recovery on self-rated health: testing the mediating role of financial strain and income. Eur J Public Health 2015;25:801-6. doi:10.1093/ eurpub/ckv108.

40 Katikireddi SV, Niedzwiedz CL, Popham F. Trends in population mental health before and after the 2008 recession: a repeat cross-sectional analysis of the 1991-2010 Health Surveys of England. BMJ Open 2012;2:e001790. doi:10.1136/bmjopen-2012-001790.

41 Kontaxakis V, Papaslanis T, Havaki-Kontaxaki B, Tsouvelas G, Giotakos O, Papadimitriou G. Suicide in Greece: 2001-2011. Psychiatriki 2013;24:170-4.

42 Laanani M, Ghosn W, Jougla E, Rey G. Impact of unemployment variations on suicide mortality in Western European countries (2000-2010). J Epidemiol Community Health 2015;69:103-9. doi:10.1136/jech-2013-203624

43 Lopez Bernal JA, Gasparrini A, Artundo CM, McKee M. The effect of the late 2000s financial crisis on suicides in Spain: an interrupted time-series analysis. Eur J Public Health 2013;23:732-6. doi:10.1093/ eurpub/ckt083.

44 Madianos MG, Alexiou T, Patelakis A, et al. Suicide, unemployment and other socioeconomic factors: Evidence from the economic crisis in Greece. Eur J Psychiatry 2014;28:39-49doi:10.4321/ S0213-61632014000100004.

45 Malard L, Chastang JF, Niedhammer I. Changes in major depressive and generalized anxiety disorders in the national French working population between 2006 and 2010. J Affect Disord 2015;178:52-9. doi:10.1016/j.jad.2015.02.027.

46 Rachiotis G, Stuckler D, McKee M, Hadjichristodoulou C. What has happened to suicides during the Greek economic crisis? Findings from an ecological study of suicides and their determinants (2003-2012). BMJ Open 2015:5:e007295. doi:10.1136/bmjopen-2014-007295.

47 Rajmil L, Medina-Bustos A, Fernández de Sanmamed MJ, MompartPenina A. Impact of the economic crisis on children's health in Catalonia: a before-after approach. BMJ Open 2013;3:e003286. doi:10.1136/bmjopen-2013-003286.

48 Reeves A, McKee M, Stuckler D. Economic suicides in the Great Recession in Europe and North America. Br J Psychiatry 2014;205:246-7. doi:10.1192/bjp.bp.114.144766.

49 Reeves A, Basu S, McKee M, Stuckler D, Sandgren A, Semenza J. Social protection and tuberculosis control in 21 European countries, 1995-2012: a cross-national statistical modelling analysis. Lancet Infect Dis 2014;14:1105-12. doi:10.1016/S1473-3099(14)70927-2

50 Regidor E, Barrio G, Bravo MJ, de la Fuente L. Has health in Spain been declining since the economic crisis?) Epidemiol Community Health 2014:68:280-2 doi:10.1136/jech-2013-202944.

51 Reile R, Helakorpi S, Klumbiene J, Tekkel M, Leinsalu M. The recent economic recession and self-rated health in Estonia, Lithuania and Finland: a comparative cross-sectional study in 2004-2010. J Epidemiol Community Health 2014;68:1072-9. doi:10.1136/jech-2014-204196.
52 Saurina C, Bragulat B, Saez M, López-Casasnovas G. A conditional model for estimating the increase in suicides associated with the 2008-2010 economic recession in England. J Epidemiol Community Health 2013;67:779-87. doi:10.1136/jech-2013-202645.

53 Tapia Granados JA, Rodriguez JM. Health, economic crisis, and austerity: A comparison of Greece, Finland and Iceland. Health Policy 2015:119:941-53. doi:10.1016/i.healthpol.2015.04.009.

54 Vandoros S, Hessel P, Leone T, Avendano M. Have health trends worsened in Greece as a result of the financial crisis? A quasiexperimental approach. Eur I Public Health 2013:23:727-31. doi:10.1093/eurpub/ckt020.

55 Zapata Moya AR, Buffel V, Navarro Yáñez CJ, Bracke P. Social inequality in morbidity, framed within the current economic crisis in Spain. Int J Equity Health 2015;14:131. doi:10.1186/s12939-015-0217-4.

56 Zavras D, Tsiantou V, Pavi E, Mylona K, Kyriopoulos J. Impact of economic crisis and other demographic and socio-economic factors on self-rated health in Greece. Eur I Public Health 2013;23:206-10. doi:10.1093/eurpub/cks143.

57 Catalano R, Goldman-Mellor S, Saxton K, et al. The health effects of economic decline. Annu Rev Public Health 2011;32:431-50. doi:10.1146/annurev-publhealth-031210-101146.

58 Stuckler D, Basu S, Suhrcke M, Coutts A, McKee M. The public health effect of economic crises and alternative policy responses in Europe: an empirical analysis. Lancet 2009;374:315-23. doi:10.1016/ S0140-6736(09)61124-7.

59 Fountoulakis KN, Gonda X, Dome P, Theodorakis PN, Rihmer Z. Possible delayed effect of unemployment on suicidal rates: the case of Hungary. Ann Gen Psychiatry 2014;13:12. doi:10.1186/1744-859X-13-12

60 Ronda E, Briones-Vozmediano E, Galon T, García AM, Benavides FG, Agudelo-Suárez AA. A qualitative exploration of the impact of the economic recession in Spain on working, living and health conditions: reflections based on immigrant workers' experiences. Health Expect 2016:19:416-26. doi:10.1111/hex.12365.

61 McMichael AJ, Woodruff RE, Hales S. Climate change and human health: present and future risks. Lancet 2006;367:859-69. doi:10.1016/S0140-6736(06)68079-3.

62 Wagenaar AC, Salois MJ, Komro KA. Effects of beverage alcohol price and tax levels on drinking: a meta-analysis of 1003 estimates from 112 studies. Addiction 2009;104:179-90. doi:10.1111/j.1360-0443.2008.02438.x.

63 McClure CB, Valdimarsdóttir UA, Hauksdóttir A, Kawachi I. Economic crisis and smoking behaviour: prospective cohort study in Iceland. BMJ Open 2012;2:e001386. doi:10.1136/bmjopen-2012 001386.

64 Filippidis FT, Schoretsaniti S, Dimitrakaki C, et al. Trends in cardiovascular risk factors in Greece before and during the financial crisis: the impact of social disparities. Eur J Public Health 2014;24:9749. doi:10.1093/eurpub/cku028.

65 Correia T, Dussault G, Pontes C. The impact of the financial crisis on human resources for health policies in three southern-Europe countries. Health Policy 2015;119:1600-5. doi:10.1016/j. healthpol.2015.08.009.

66 Rachiotis G, Kourousis C, Kamilaraki M, Symvoulakis EK, Dounias G, Hadjichristodoulou C. Medical supplies shortages and burnout among greek health care workers during economic crisis: a pilot study. Int J Med Sci 2014;11:442-7. doi:10.7150/ijms.7933.

(c) BMJ Publishing Group Ltd 2016

Supplementary appendix: Supplementary material 